\title{
Adaptive evolution as a biological analogue of sustainable energy technologies
}

\author{
Semen Podvalny ${ }^{1, *}$ and Eugeny Vasiljev $^{1}$ \\ ${ }^{1}$ Voronezh State Technical University, 394026, Russia
}

\begin{abstract}
An analogy is drawn between complex energy technologies and the evolution of biological structures. The subject is a general property of the variety of biological and ecological systems providing their existence and development in the conditions of critical changes of the external environment. The mechanisms of realization of this variety are formulated as principles: the multilevelness of both the structure and functioning of these systems; variety and division of functions, modularity of their components. At the pre-biological stage of the emergence of life as a phenomenon, these principles did not allow the overwhelming domination of any unique type of macromolecules and provided their joint, yet competing development. At the level of populations, the evolution can originate only if the speed of their internal accumulation of genetic variety surpasses the speed of a stream of events in the changing environmental conditions. In ecological systems, the stability of evolutionary processes is provided due to the internal formation of the multilevel hierarchical structure, which is combined with the variety of individual adaptive functions of different types at each level of an ecosystem. The concept of multialternativity offered as a way of understanding the mechanisms of evolution and adaptation in living organisms gives the opportunity of purposeful reproducing these mechanisms in the control systems of complex energy objects and increasing the stability of their functioning.
\end{abstract}

\section{Introduction}

Process of evolution of live organisms in the conditions of critical changes of the external environment must lead to the formation at biologically different systems having the uniform structural concept providing a steady existence and development of these systems [1-3]. Understanding of the steady evolutional mechanisms is necessary for the correct idea of the prospects for creating sustainable energy technologies [4]. As the uniform concept uniting the abovementioned mechanisms the evolutionary concept of multialternativity is proposed including the principles [5-7]:

- Multilevelness;

- Modularity;

- Variety and division of functions.

\footnotetext{
* Corresponding author: vgtu-aits@yandex.ru
} 
The examples given below explain the realization of these principles in various biological structures.

\section{Methods and mechanisms of adaptation in complex structures}

\subsection{Principle of a multilevelness}

Classical sample of the multilevel organization of adaptive mechanisms in biological systems is the process of homeostasis which is carried out by means of a control system with two or more levels of hierarchy. Some of them support the preset stable condition of an organism during minor changes in the condition of an object, whereas the others reacts to the critical deviations of this state only.

In Fig. 1 the schematic representation of such two-level control is shown:

- The parametrical level of control stabilizing only the preset condition of a system at noncritical deviations of its parameters;

- The structural level launching the mechanisms of essential reorganization of a system which have qualitatively new character, in particular, it can be faltering, stepped, generating the alternative control structures.
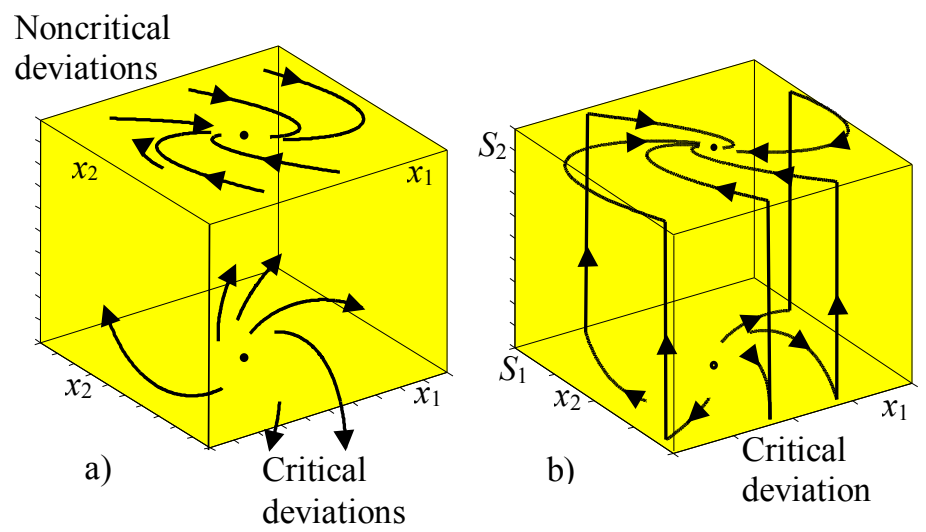

Fig. 1. Representation of multilevel control mechanism: a) parametrical level; b) structural level transition from structure $S_{1}$ to structure $S_{2}$.

A particular example of homeostasis is the multilevel control system to regulate sugar content in human blood is presented schematically in Fig. 2.

The principle of a multilevelness or hierarchy is the integral condition of stability of any complex ecological system, forming a trophic chain of the circulation of substance and energy. 


\subsection{Principle of modularity}

The essence of the modularity principle presumes that the formation of any new structure occurs on the basis of a new combination of already existing simple elements- the modules. As a result of such unification of the "construction elements" the possibility of an unlimited high-quality improvement of complex systems appears on the basis of elementary, invariable and the simplest components.

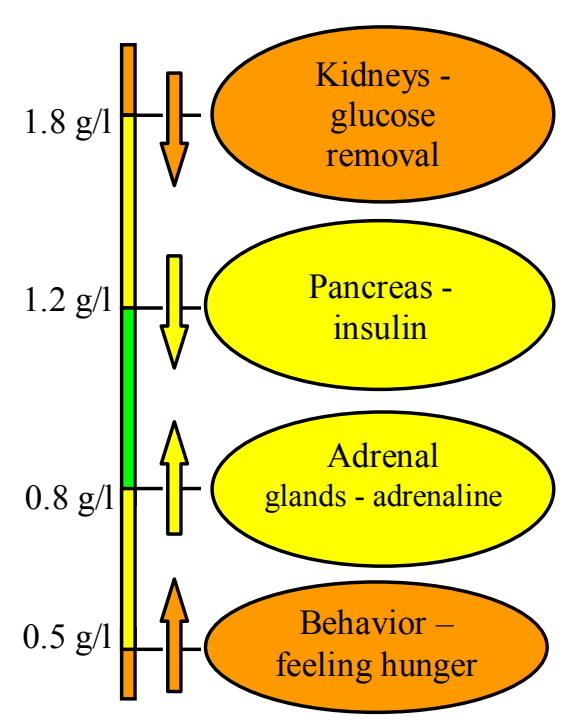

Fig. 2. Example of multilevel regulation of sugar in human blood (normal content is $0.8-1.2 \mathrm{~g} / \mathrm{l}$ ).

Biological illustration of the principle of a modularity is a creation of the existing variety of proteins on the basis of combinations of only 20 main amino acids, each of them is defined in a genetic code by the sequence of the triplets containing, in turn, only four nucleotides of A,G,T,C (Fig. 3).

Example of DNA creation from 4 polymers: adenine, thymine, guanine, cytosine

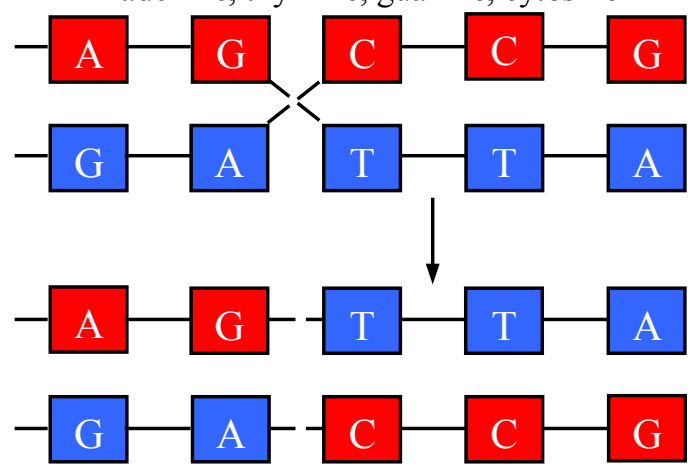

4 polymers, 20 amino acids, over $10^{26}$ types of proteins

Fig. 3. The principle of a modularity in the DNA creation. 


\subsection{Principle of variety and division of functions}

The main condition of the existence and evolution of biological systems in the conditions of external environment influence is a sufficient and moreover, the excessive variety of its taxons [8]. It's due to them in the situations when the changes of the habitat become adverse for the existence of any element of a system, its place is taken by one or several other biological groups capable to restore the broken balance in said system.

A measure of a variety in one taxon may be the information entropy $H$ according to Shannon [9]:

$$
H=-\sum_{i=1}^{n} p_{i} \log _{2} p_{i} ; \quad p_{i}=\frac{N_{i}}{N} ; \quad N=\sum_{i=1}^{n} N_{i},
$$

where: $n$ - the quantity of elements in a taxon; $N$ - power of the $i$ element.

If the competition and natural selection lead to the reduction of an intraspecific variety, this reduction are followed simultaneously with compensation growth of a variety of genera, i.e. a variety of higher hierarchical level of a biosystem.

The important adaptive mechanism of separate system levels is the mechanism of specialization and division of functions providing a stable existence of a taxon in various conditions [10].

The biological examples of an emergence of such specialization are, e.g., the origination of the early maturity and late maturity forms of plants of the same species blossoming in different seasons up to the formation of spring and winter forms; the division of functions between the wing pairs of beetles: forward rigid wing sheaths give strength, durability and compactness to a beetle body, expedient enough for movement in water, soil or wood, and soft rear wings providing the ability to flight (Fig. 4).

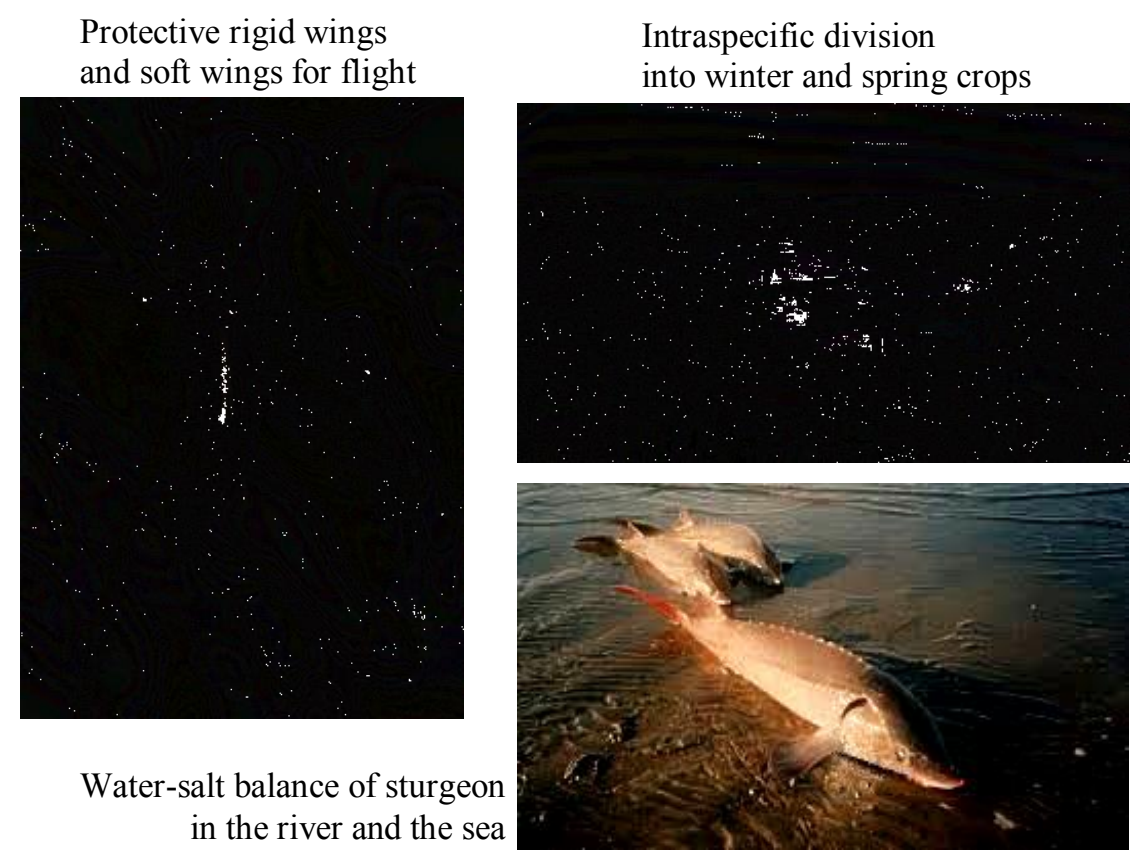

Fig. 4. Examples of the division of functions in various species, Source: https://www.zin.ru/Animalia. 
Similar division of functions is revealed in the Rhodococcus actinebacteria capable to exist in extreme habitats with oil pollution or high content of mineral salts [11].

This ability is caused by differentiation in their life cycle of four cell types forming various combinations of intercellular cooperation in colonial populations of bacteria depending on the environmental conditions.

The principle of the division of functions can be observed in the sea-river-sea migrating fish (see Fig. 4) where they face essential changes of water salinity and need of reorganization of a method of maintaining the water-salt balance.

The best fit to a change of salinity is observed in the species of fish with the active strategy of adaptation resulting in the complete substitution of osmotic regulation. Such osmotic conformity became possible due to the permanent existence in a branchiate epithelium of fishes of the ion-filtering cells (ionocytes) of both the sea, and freshwater types. Depending on a salinity of the environment the corresponding type of cells becomes more active.

Similar example is evolution of animals' sight of those adapted from nocturnalism to a daytime activity. This transition led to an emergence in the primacies of two types of photosensitive cells: the highly sensitive sticks providing twilight, not a color sight, and the cells - the cones - that are less sensitive but adapted for the distinction of colors (Fig. 5).

Such division of functions of visual receptors allowed to expand significantly an ecological niche of the highest mammals.

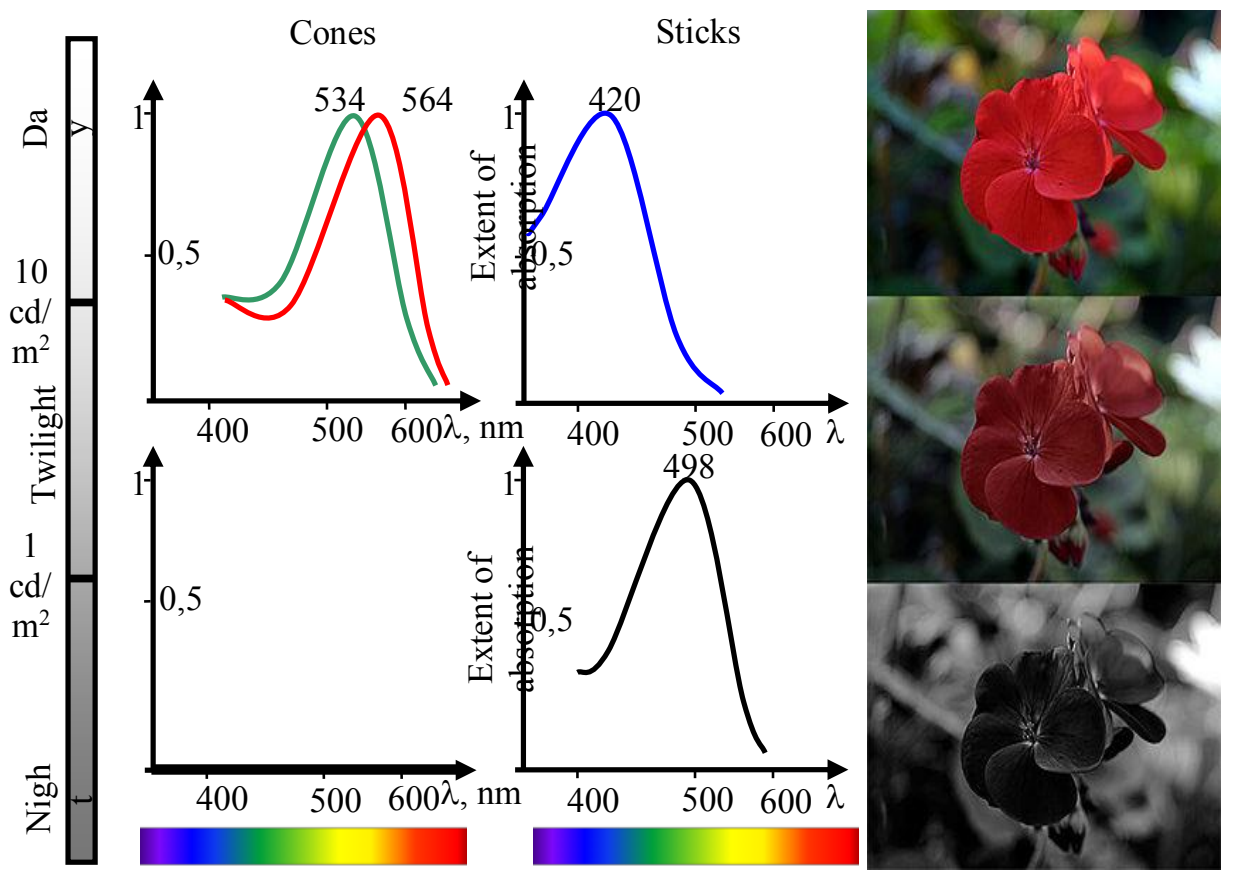

Fig. 5. Example of the division of functions of twilight and color sight, Source: http://cyclowiki.org/.

Unique adaptive property of fauna is the existence in live organisms that were initially unspecialized: the stem cells that are capable, if necessary, to differentiation to any cell or tissue with extremely specialized functions (Fig. 6). 


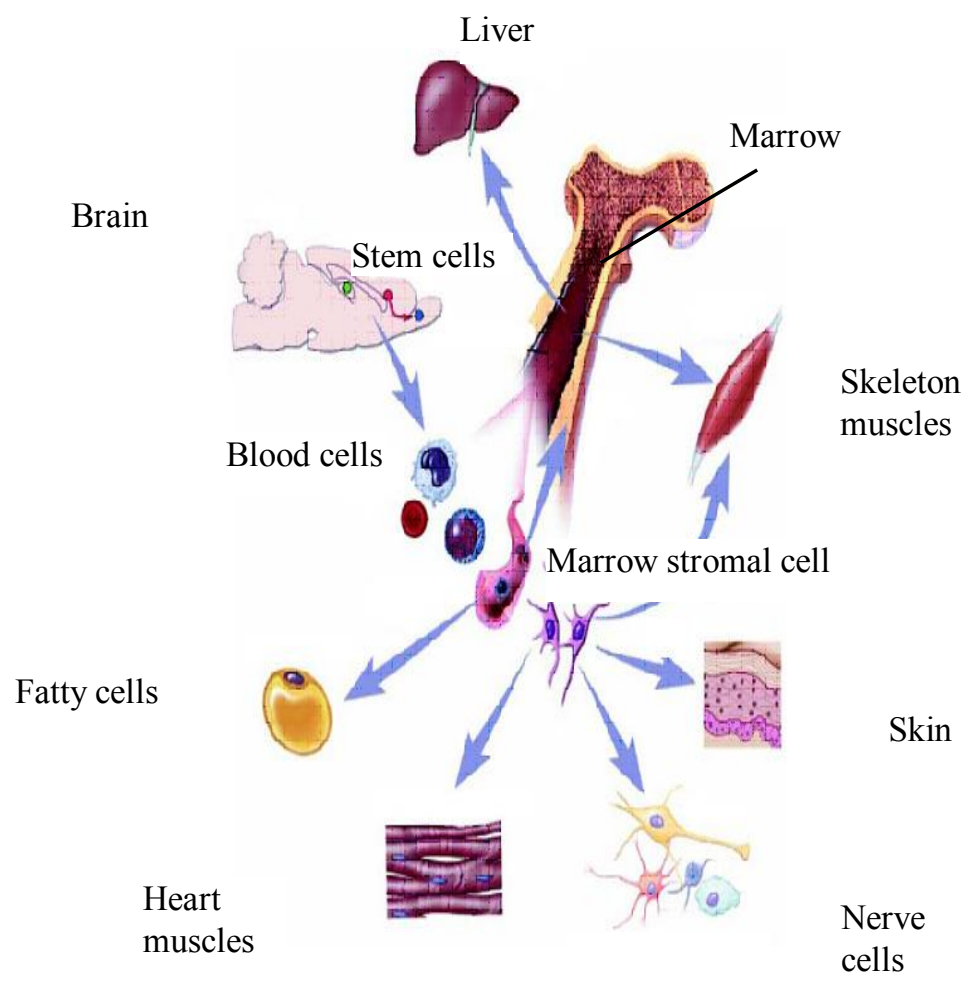

Fig. 6. Example of differentiation of stem cells functions, Source: https://stemcells.nih.gov.

\section{Results}

Considering the results of the research from the positions of applicability, a series of rather simple structural principles of multialternativity can be drawn thus obtaining the content of sustainable energy technologies, i.e.:

- The principle of multilevelness and hierarchy of both the structure and functioning that are mandatory for the emergence of homeostasis in the energy systems;

- The principle of variety and division of functions of subsystems which gives way to realization of an adaptive transfer of control between them as well as a generally high level of system's flexibility in the conditions of its open interaction with a changing external environment;

- The principle of modularity generating a combinatory variety of options of a structure and possible operating modes of a system utilizing just a limited number of different standard modules.

Practical realization of these principles removes the "the curse of dimensionality" which still remains an actual problem in the energy systems of high complexity.

\section{Discussion of results}

Let's discuss the system-forming value of multialternativity principles. 
The principles of multialternativity of structure and functioning of biological systems stated above are well shown in a widely known and conventional property of the variety of wildlife [12-14].

This property originated already at a pre-biologic stage of emergence of life in the macromolecular structures - the quasitypes and sysers [15]. The analysis of models of these structures shows that the necessary condition of an evolution of the macromolecules capable to reproduction was the realization of the principles of multialternativity disclosed above e.g. [16]:

- A considerable variety of the macromolecules of various types competing between themselves in a limited space;

- Selectivity of evolutionary mechanisms of molecules of different types;

- Existence of the mutual mutational streams between the molecules of different types providing the variability in the absence of the crossing mechanism inherent only in live structures with the genetic principle of inheritance.

In the biological systems at the initial level of evolution, i.e., the populations, the principle of multialternativity manifests itself as the requirement of the genetic variety updating (updating the population gene pool) with a sufficient speed that would surpass the speed of changes of the environmental conditions [17,18].

Usually this requirement is connected with a concept of critical population quantity which, in actual practice, is controlled much easier, than the genetic variety. At the decrease in the quantity of a population below the critical value the speed of genetic variety accumulation decreases so that the population will not be able to adapt in due time to the ecological changes and dies out.

Let's notice, as it was noted above, that the genetic variety has the combinatory nature, i.e. it is caused by a "modular" structure of genes.

At the level of large ecosystems the principles of multialternativity are expressed as follows [19-23]:

- At the structural level - in the form of emergence of hierarchically developed trophic chain: the producers, primary and secondary consumers, decomposers, - the ecosystem which is getting isolated through mineral components;

- At the local levels - having the variety of the types occupying various ecological niches.

Getting out of the food chain by some species results in occupying its place by other species which, generally, was in depression before, but contained in its gene pool an ability to adapt to new conditions.

Thanks to multialternativity at all levels of ecological system the interaction mechanisms exist that are not limited to usual competitive replacement: there are more complex relations, from symbiosis to the "predator - victim" relation.

Thus, in an ecosystem the most developed mechanism of stabilization of its existence is implemented, i.e.: the variety in a system is maintained not only by the trans-species competition, but also due to the regulating influence of adjacent hierarchical levels.

The mechanisms listed can fully serve as a biological prototype of sustainable energy technologies.

\section{Conclusion}

Technologies for creating sustainable energy systems are currently facing the problem of "the curse of dimensionality".

Focusing on the biological origins of the problem being considered shows that the variety of conditions of the environment in the course of evolution of live organisms have 
led to the development of their corresponding adaptive mechanism: the multialternativity of functioning.

The concept of multialternativity offered in this paper as a way of understanding the mechanisms of evolution and adaptation in living organisms gives the opportunity of purposeful reproducing these mechanisms in the sustainable energy technologies. This concept determines the "non-complicating simplicity" principle as an answer to the challenges of complex energy systems development.

\section{References}

1. V.A. Krassilov, BP 4-1, 3-6 (2015) doi: 10.17581/bp.2015.04104

2. E.M. Galimov, Geochem. Int. 54-13, 1096-1135 (2016) doi: 10.1134/S001670291613005X

3. A.G. Ponomarenko, A.A. Prokin, Paleontol. J. 49-13, 1383-1412 (2015) doi: 10.1134/S0031030115130080

4. V.Y. Dmitriev, Paleontol. J. 45, 6, 705-708 (2011) doi: 10.1134/S0031030111060049

5. S.L. Podvalny, E.M. Vasiljev, Autom. Remote Control 76-8, 1471-1499 (2015) doi:10.1134/S0005117915080123

6. S.L. Podvalny, E.M. Vasiljev, Autom. Remote Control 76-2, 311-317 (2015) doi: 10.1134/S0005117915020101

7. S.L. Podvalny, E.M. Vasiljev, V.F. Barabanov, Autom. Remote Control 75-10, 18861891 (2014) doi: 10.1134/S0005117914100166

8. E.D. Cope, The primary factors of organic evolution (Wentworth Press, Sydney, 2016)

9. R.A. Rodríguez, A.M. Herrera, R. Riera, J.D. Delgado, Á. Quirós, M.E. Perdomo, J. Santander, J.V. Miranda, M.J. Fernández-Rodríguez, A. Jiménez-Rodríguez, J.M. Fernández-Palacios, R. Otto, C.G. Escudero, R. Ma Navarro-Cerrillo, Ecol. Model. 296, 24-35 (2015) doi: 10.1016/j.ecolmodel.2014.10.017

10. N.N. Iordansky, Biol. Bull. 43, 1195-1202 (2016) doi: 10.1134/S1062359016110066

11. K.M. Cheremnykh, I.B. Ivshina, N.A. Luchnikova, V.V. Grishko, J. Hazard. Mater. 346, 103-112 (2018) doi: 10.1016/j.jhazmat.2017.12.025

12. Convention on Biological Diversity / Treaty Series (United Nations, New York, 2001)

13. N. Nikisianis, G.P. Stamou, Acta Biotheor. 64, 33-64 (2016) doi: 10.1007/s10441-0159272-X

14. P. Visconti, V. Elias, P. Sousa, M. Fischer, V. Ali-Zade, A. Báldi, S. Brucet, E. Bukvareva, K. Byrne, P. Caplat, A. Feest, C. Guerra, R. Gozlan, D. Jelić, Z. Kikvidze, A. Lavrillier, X. Le Roux, O. Lipka, P. Petrík, B. Schatz, I. Smelansky, F. Viard, The ipbes regional assessment report on biodiversity and ecosystem services for Europe and central Asia (IPBES, Bonn, 2018)

15. R.A. Fisher, The genetical theory of natural selection (Oxford University Press, Oxford, 2011)

16. V.G. Red'ko, BICA, 22, 95-103 (2017) doi: 10.1016/j.bica.2017.10.002

17. L. Zamdborg, A.V. Spirov, D.M. Holloway, J.J. Merelo, V.F. Levchenko, Inf. Sci. 306, 88-110 (2015) doi: 10.1016/j.ins.2015.02.012

18. C. Venjakob, A.M. Klein, A. Ebeling, T. Tscharntke, C. Scherber, Ecol. and Evol. 6, 2249-2261 (2016) doi: 10.1002/ece3.2026 
19. D.U. Hooper, F.S. Chapin III, J.J. Ewel, A. Hector, P. Inchausti, S. Lavorel, J.H. Lawton, D.M. Lodge, M. Loreau, S. Naeem, B. Schmid, H. Setälä, A.J. Symstad, J. Vandermeer, D.A. Wardle, Ecol. Monographs 75, 3-35 (2005) doi: 10.1890/04-0922

20. J.-F. Arnoldi, A. Bideault, M. Loreau, B. Haegeman, J. Theoretical Biol. 436, 79-92 (2018) doi: 10.1016/j.jtbi.2017.10.003

21. N. Rooney, K. Mccann, G. Gellner, J.C. Moore, Nature 442, 265-269 (2006) doi: 10.1038/nature04887

22. M.V. Vinarski, N.I. Andreev, S.I. Andreeva, E.A. Lazutkina, I.E. Kazantsev, A.V. Karimov, J. Biol. Invasions 6-3, 137-147 (2015) doi: 10.1134/S2075111715030078

23. K. Grunewald, O. Bastian, E.N. Bukvareva, A.V. Zimenko, V.I. Grabovsky, H. Schmauder, NTLNB 91-4, 170-178 (2016) doi: 10.17433/4.2016.50153389.170-178 